\title{
The antigenic determinant that defines thymic nurse cells is expressed by thymic epithelial progenitor cells
}

\author{
Rajendra V. E. Chilukuri ${ }^{1}$, Viral K. Patel ${ }^{1}$, Marcia Martinez ${ }^{2}$, Jerry C. Guyden ${ }^{1}$ and Michael D. Samms ${ }^{1 *}$ \\ Department of Biology, The City College of New York, New York, NY, USA \\ ${ }^{2}$ Biology, Tuskegee University, Tuskegee, AL, USA
}

\author{
Edited by: \\ Atsushi Asakura, University of \\ Minnesota, USA \\ Reviewed by: \\ Yousuke Takahama, University of \\ Tokushima, Japan \\ Maria Guadalupe Reyes-Garcia, \\ National Autonomous University of \\ Mexico, Mexico \\ *Correspondence: \\ Michael D. Samms, Department of \\ Biology, The City College of New \\ York, MR-526, 160 Convent Avenue, \\ New York, NY 10031, USA \\ e-mail:mdsamms59@gamil.com
}

Stromal thymic epithelial cells with the multicellular structure unique to thymic nurse cells (TNCs) express the pH91 antigen on their cell surfaces. The multicellular TNC-complexes develop through an intimate association between $\alpha \beta T C R^{+} \mathrm{CD}^{+}{ }^{+} \mathrm{CD} 8^{+}$thymocytes and pH91-expressing cortical epithelial cells. TNCs participate in MHC-restriction and exhibit epithelial cell progenitor characteristics. In this report, we show that as early as E11.5 stage of thymus development, the pH91 antigen is expressed in association with $\mathrm{K} 8, \mathrm{~K} 5$, Foxn1, and p63. The expression of these epithelial progenitor markers along with the pH91 antigen persists throughout thymic development in the murine thymus. At E13.5, pH91+ cells express relatively low levels of MHC class II. After E17.5, the first multicellular TNC complexes are recognizable along with increased cell surface expression of MHC class II. Our data suggest that epithelial cells bearing the "progenitor phenotype" develop into the multicellular TNCs.

Keywords: thymic nurse cells, $\mathrm{K}^{+} \mathrm{K} 8^{+}$, Foxn1, p63, thymic progenitor cells, $\mathrm{mTEC}$ and $\mathrm{cTEC}$

\section{INTRODUCTION}

The bipotent population of cells that give rise to both cortical (cTECs) as well as medullary epithelial (mTECs) cells that participate in the maintenance of self-tolerance within the organism (Gill et al., 2002; Baik et al., 2013) has received much attention in recent years. Previous studies showed thymic epithelium (TECs) to be generated exclusively from the endoderm (Le Douarin and Jotereau, 1975; Gordon et al., 2004). By embryonic day 12, E12, the structural morphology of the thymus becomes visible, with the initial separation of the cortex and the medulla (Klug et al., 1998, 2002). This morphology results in a visibly densely packed cortex surrounding a markedly more defused medulla. The cells that comprise the cortex or the medulla can be distinguished by their cytoplasmic keratin profiles (Klug et al., 1998). Cells of the cortex express cytokeratin 8 (K8) but not cytokeratin 5 (K5), while the inverse expression pattern was found for cells of the medulla (Klug et al., 1998). This keratin expression pattern is preceded in the embryological thymus by cells that express both K8 and K5 (Gill et al., 2002; Klug et al., 2002). $\mathrm{K}^{+} \mathrm{K}^{+}$cells were shown to appear between E11 and E12 (Gill et al., 2002; Klug et al., 2002). Since double positive epithelial cells appear before $\mathrm{K} 8^{+} \mathrm{K}^{-}$or $\mathrm{K}^{-} \mathrm{K}^{+}$single positives, it has been suggested that $\mathrm{K}^{+} \mathrm{K}^{+}$cells are progenitors of the both single positive subsets, and give rise to cells that develop into the medulla or cortex. This theory is supported by studies in which $\mathrm{T}$ cell development is blocked early during the differentiation process (Klug et al., 1998). Such genetic mutations produce an "immature" thymus, which produce a stromal epithelial population that is predominantly $\mathrm{K} 8{ }^{+} \mathrm{K} 5^{+}$cells.

Besides cytokeratin characterization, other studies are providing important information regarding the common bipotent cell population that result in both cTECs as well as mTECs (Baik et al., 2013; Alves et al., 2014). The findings of one study showed that TEC progenitors undergo an orchestrated sequence of events leading to the concomitant expression of the cTEC identifier CD205 and also the Receptor Activator of NF-kB (RANK), the mTECs regulator. The DC205 ${ }^{+}$cells were shown to develop and produce functionally capable microenvironments consisting of CTECs and mTECs expressing the autoimmune regulator Aire (Baik et al., 2013; Alves et al., 2014). Another study employed the B5t-Cre-loxP mediated GFP expression system strongly support the notion that Aire-expressing medullary epithelial cells arise from B5t producing progenitor cells (Ohigashi et al., 2013). Further, other evidence suggest that Aire+ mTECs express the tight-junction components claudin- 3 and claudin- 4 early in thymus ontogeny (Hamazaki et al., 2007). These results suggest that heterogeneous populations of progenitor cells may differentiate into cTECs and/or mTECs.

The expression of transcription factors during early thymic organogenesis has provided some insights into the characterization of thymic epithelial progenitors (Manley, 2000; Gordon et al., 2001). Foxn1 has a winged-helix/forkhead DNA binding domain as well as a transcriptional activation domain (Biggs et al., 1999; Kops et al., 1999), and is the earliest marker known to indicate the commitment to the epithelial development of the thymus (Manley, 2000; Gordon et al., 2001). Foxn1 mutants have been shown to block the expansion of TEC, and resemble mutant mice with a block in thymocyte development, in that the epithelial development does not go beyond the $\mathrm{K}^{+} \mathrm{K}^{+}$phenotype (Nehls et al., 1996). Another transcription factor, p63, an homolog of p53 is important in the maintenance of the proliferative potential of epithelial cells (Bleul et al., 2006; Gillard and Farr, 2006; Senoo et al., 2007). Its expression is up-regulated in putative TEC stem cells (Gillard and Farr, 2006). Other reports suggest that p63 
functions in the commitment of the cells to the epithelial linage in the thymus (Blanpain and Fuchs, 2007; Candi et al., 2007). The expression of p63 is detectable by $\mathrm{E} 12$ within $\mathrm{K}^{+} \mathrm{K}^{+}$cells in the developing thymus (Senoo et al., 2007).

In a previous report (Hendrix et al., 2010), we showed cells with the morphology of thymic nurse cells (TNCs) to express the TNC-antigen, pH91, K8, and $\mathrm{K} 5$ along with the transcription factor p63 (Hendrix et al., 2010). The pH91 antigen has been previously shown to participate in TNC binding and internalization of immature thymocytes at the triple positive stage of development (Pezzano et al., 1998). Further, blocking studies showed this antigen to be vital to the survival of the developing thymus (Pezzano et al., 1998). Although pH91 is an orphan antigen, its role during $\mathrm{MHC}$ restriction has been shown to be important to the development of the thymus (Pezzano et al., 1996; Samms et al., 1999; Martinez et al., 2007).

The ontogenic expression of $\mathrm{pH} 91$ antigen in conjunction with Foxn1 has not been previously investigated. In this report, we show the $\mathrm{K}^{+}{ }^{+} \mathrm{K}^{+} \mathrm{p} 63^{+}$TNC-subset to express the transcription factor, Foxn1. Further, we show the onset of pH91 expression to be concomitant with that of Foxn 1 within the third pharyngeal pouch on E11.5 day of development. A subset of cells with the $\mathrm{pH} 91^{+}$Foxn $1^{+}$phenotype persists throughout ontogeny and during the early neonatal stage of development. These data suggest that a subset of cells previously defined as thymic epithelial progenitors express the TNC-antigen, $\mathrm{pH} 91$.

\section{MATERIALS AND METHODS ISOLATION OF TNCS AND THYMOCYTES}

Isolation of cells were performed as previously described (Hendrix et al., 2010). Briefly, C57BL/6 mice (Jackson Laboratory, Bar Harbor, ME) were dissected aseptically and the thymi were removed. Thymi were slightly disrupted with fine needles and subjected to enzymatic digestion in a solution of $0.015 \%$ collagenase D (Sigma Aldrich, St Louis, MO), 0.01\% DNAse I (Sigma Aldrich), and $25 \mathrm{ml}$ of trypsin (GIBCO, Carlsbad, CA) along with gentle agitation. The solution was changed every $10 \mathrm{~min}$ until the thymi were completely digested. The resulting cells were subjected to $1 \times \mathrm{g}$ gradient separation in fetal bovine serum (Atlas Biological, Fort Collins, CO) at $4^{\circ} \mathrm{C}$ to enrich TNC numbers. Thymocytes were obtained by the mechanical disruption of thymi obtained from 4 to 6 week old C57BL/ 6 mice. Macrophage depletion was accomplished by negative sorting using CD11b Microbeads (Miltenyi Biotech, Auburn, CA).

\section{TIMED PREGNANCY AND THYMIC SECTIONS}

Experiments were conducted as previously described (Hendrix et al., 2010). C57BL/6 mice were mated overnight; females were separated the next day upon detection of a vaginal plug. For early timed embryo (E11.5 and E12.5 sections) the entire fetus was embedded in OTC medium. Form E13.5 onwards, individual lobes were isolated and embedded in OTC medium (Richard Allan Scientific, Kalamazoo, MI). Thymic sections, $10 \mu \mathrm{m}$ in thickness were made using a Leica CM1950 Cryostat. Sections were mounted onto Bond-Rite microscope slides (Richard Allan Scientific, MI) for immunostaining and sections were analyzed using a Zeiss LSM510 Confocal Microscope. Phenotypic subsets of embryonic cells obtained from E11.5 and E12.5 were microscopically enumerated; more than 550 cells were counted for each embryonic time point.

\section{IMMUNOSTAINING OF TNCs AND THYMIC SECTIONS}

Experiments were conducted as previously described (Hendrix et al., 2010). Briefly, isolated TNCs were deposited onto glass slides using a Thermo Scientific Shandon Cytospin 4. Thymic sections or isolated TNCs were fixed in 2\% paraformaldehyde (Baker, Phillipsburg, PA) for $30 \mathrm{~min}$ followed by 3 washes with PBS (GIBCO). Sections were blocked and permeabilized in 3\% BSA (Fisher Scientific, Pittsburg, PA), 0.1\% Triton-X (Fisher Scientific) in PBS. Samples were incubated with primary and secondary antibodies at $37^{\circ} \mathrm{C}$ for $1 \mathrm{~h}$ each. Samples were mounted in ProLongGold antifade with DAPI (Molecular Probes, Carlsbad, CA). Images were acquired using the Zeiss LSM510 Confocal Microscope. Primary antibodies used were as

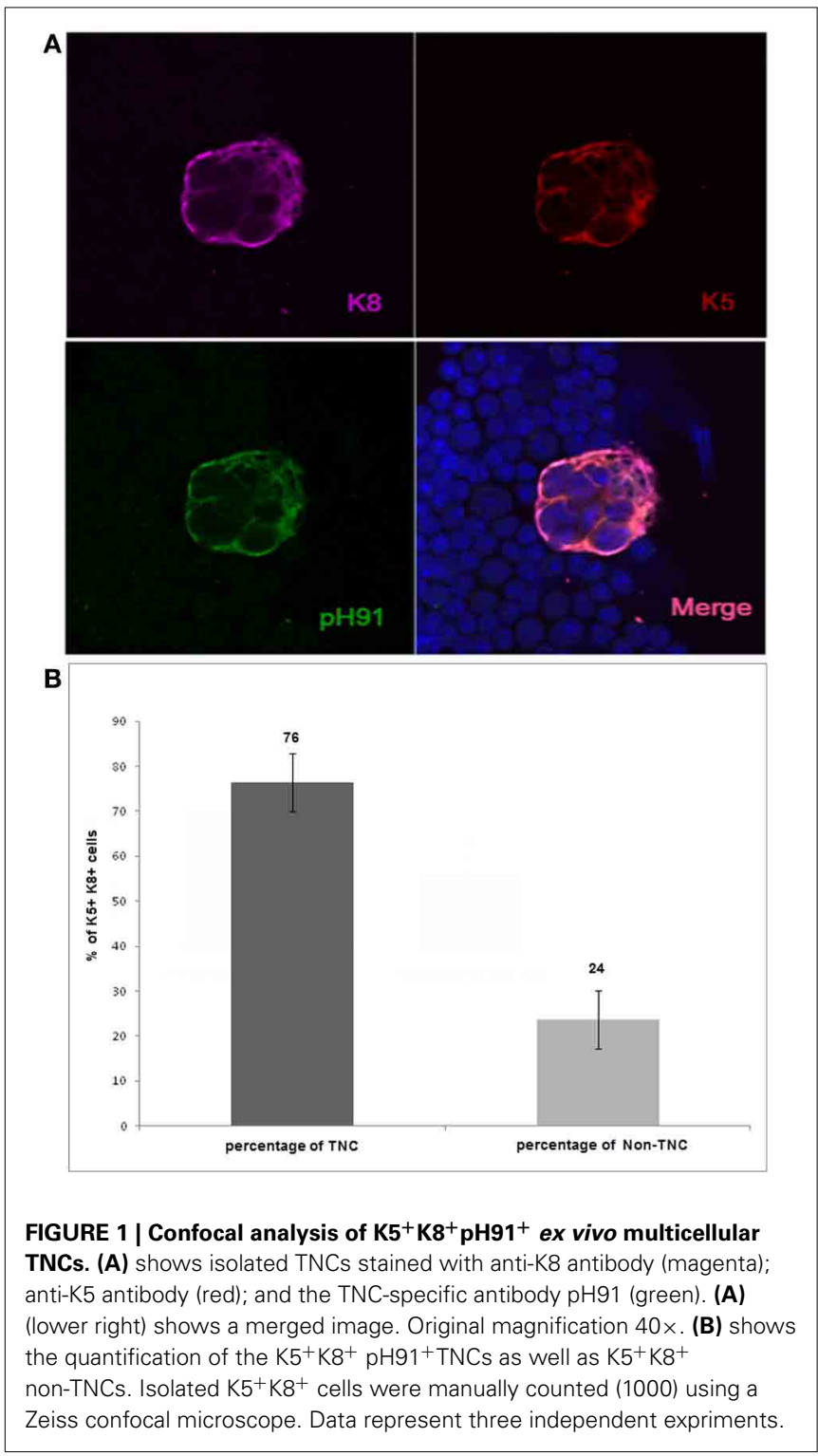


follows: rat anti-mouse pH91 monoclonal antibody (IgG2a), K8 TROMA-I (IgG2a) (Developmental Studies Hybridoma Bank, Iowa City, IA), chicken anti-mouse K8 polyclonal antibody (IgY) (Abcam, Cambridge, MA), goat anti-rabbit K5 polyclonal antibody PRB-160B (IgG) (Covance, Princeton, NJ), rabbit anti-goat $\Delta$ Np63 (N-16): sc-8609 (Santa Cruz Biotechnology, Santa Cruz, CA), rabbit anti-Foxn1 polyclonal antibody (IgG) H-270 (Santa Cruz Biotechnology), antibody FITC-conjugated anti-mouse MHC class II (Miltenyi Biotech), biotinylated anti-mouse $\alpha \beta$ TCR (BD Pharmingen, San Jose, CA), APC-conjugated CD4 (BD
Pharmingen), PE-conjugated CD8 (BD Pharmingen), FITCconjugated Thy 1.2 (BD Pharmingen), FITC-conjugated rat IgG2a isotype control (BD Pharmingen), and TRITC-conjugated rabbit IgG2a isotype control (BD Pharmingen). Secondary antibodies used are as follows: FITC-conjugated mouse anti-rat IgG2a (BD Pharmingen), APC-conjugated donkey anti-chicken IgY (Jackson ImmunoResearch Laboratories, West Grove, PA), TRITC-conjugated goat anti-rabbit IgG (Jackson ImmunoResearch Laboratories), APC-conjugated donkey anti-rabbit IgG (Jackson ImmunoResearch Laboratories),
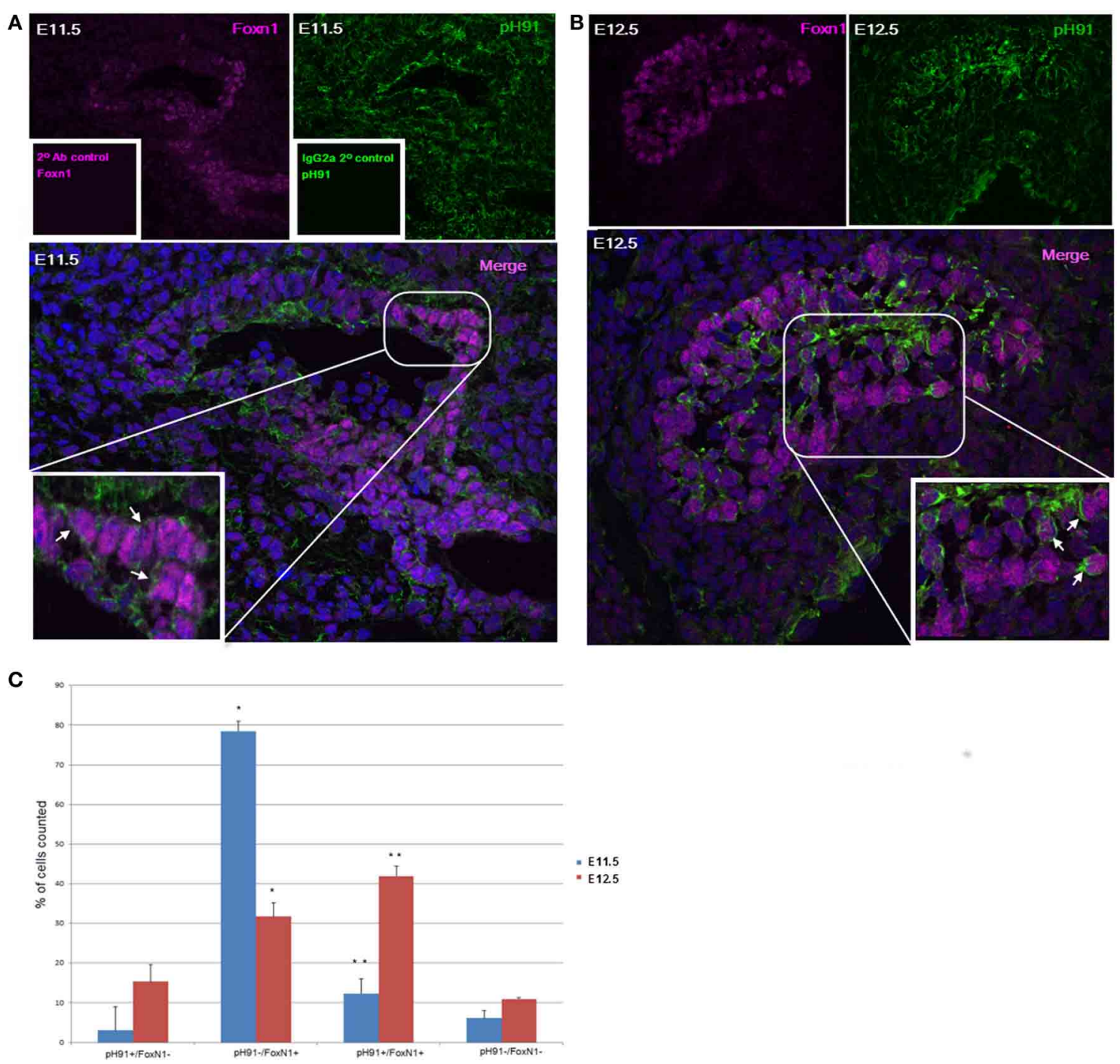

FIGURE 2 | Thymic embryonic sections stained with pH91 and anti-Foxn1 antibody. (A) shows embryonic staining with anti-Foxn1 antibody (magenta), left panel; along with pH91 (green) right panel of E11.5 mouse thymic primordium. Expression of Foxn1 is localized toward the ventral region of the embryo whereas pH91 expression is seen throughout the entire thymic and para-thyroid primordium. The merged image (lower panel) and inset (enlarged) show pH91+ cells in association with Foxn $1^{+}$cells (arrows). The insets of the upper left (inset) and upper right (inset) panels show secondary antibody control for Foxn1 antibody (magenta) and IgG2a isotope control for pH91 (green). (B) shows staining of E12.5 thymic anlagen with anti-Foxn1 antibody, left panel (magenta) and $\mathrm{pH} 91$, right panel (green). The merged image (lower panel) and inset (enlarged) show an association of Foxn $1^{+}$with $\mathrm{pH} 91^{+}$cells (arrows). Magnification 40x. (C) shows the relative percentage of the various phenotypic subtypes present at E11.5 and E12.5 respectively. The pH91-/Foxn $1^{+}$phenotype shows a significant increase $\left.{ }^{*} P<0.001\right)$ between E11.5 and E12.5, $(n=6)$. The $\mathrm{pH} 91^{+} /$Foxn1+ subset show statistical significance $\left({ }^{* *} P<0.05\right)$ between E11.5 and E12.5 $(n=6)$. Five-hundred and fifty embryonic cells were counted for (C). The images are representative of three independent expriments. 
TRITC-conjugated donkey anti-rabbit IgG (Jackson ImmunoResearch Laboratories), TRITC-conjugated donkey anti-goat IgG (Jackson ImmunoResearch Laboratories), TRITCconjugated rabbit anti-goat IgG (Jackson ImmunoResearch Laboratories), and TRITC-conjugated streptavidin (BD Pharmingen).

\section{FACS ANALYSIS OF ISOLATED TNCS}

Pregnant mice were euthanized and embryonic pups removed at E13.5 or E16.5 or E18.5 stages of development. Thymi from each embryonic stage were subjected to enzymatic digestion. Isolated cells were washed in ice cold EDTA/FACS buffer. Then, $5 \times 10^{5}$ cells were then co-stained with pH91 mAb and anti-MHC II primary antibodies in $30 \mu \mathrm{l}$ residual volume of EDTA/FACS buffer for $30 \mathrm{~min}$ at $4^{\circ} \mathrm{C}$. Preparations were washed 3 times with $500 \mu \mathrm{l}$ of buffer and incubated with secondary reagents in residual volume. Finally, cells were washed 3 times and resuspended in a $300 \mu$ l volume of EDTA/FACS buffer for analysis using a BD FACS analyzer.

\section{STATISTICAL TEST}

The student two-tailed $t$-test was used in the statistical analysis of data.

\section{RESULTS}

\section{TNCs EXPRESS PROGENITOR PHENOTYPE}

Thymic epithelial cells within the cortico-medullary junction (CMJ) that express both $\mathrm{K} 5$ and $\mathrm{K} 8$ have been proposed to be thymic epithelial progenitor cells (Klug et al., 2002). In a recent publication, we showed in tissue section that $\mathrm{K} 8$ and $\mathrm{K} 5$ positive TNCs reside within the CMJ of the thymus (Hendrix et al., 2010). To determine the frequency of these cytokeratin subsets, we isolated TNCs and co-stained with antibodies to $\mathrm{K} 8$ and $\mathrm{K} 5$ as well as the $\mathrm{pH} 91$-antigen. The results show that $76 \%$ of the epithelial cell population expressed both $\mathrm{K} 8$ and $\mathrm{K} 5$ and portrayed the multicellular morphology of TNCs, whereas $24 \%$ of the $\mathrm{K}^{+} \mathrm{K}^{+}$ cells did not exhibit the distinctive multicellular TNC phenotype (Figures 1A,B). Cells with the multicellular structures of TNCs that expressed the K5 only phenotype were not detected (data not shown).

\section{EXPRESSION OF Foxn1 AND pH91-ANTIGEN IN THYMIC PRIMORDIUM}

Previous studies implicate the expression of the transcription factor Foxn1 to be required for development of epithelial cells in the thymus (Gordon et al., 2001; Popa et al., 2007). We sought to investigate the relationship between the TNC-antigen, pH91 and Foxn1 during thymic development (Figure 2). The
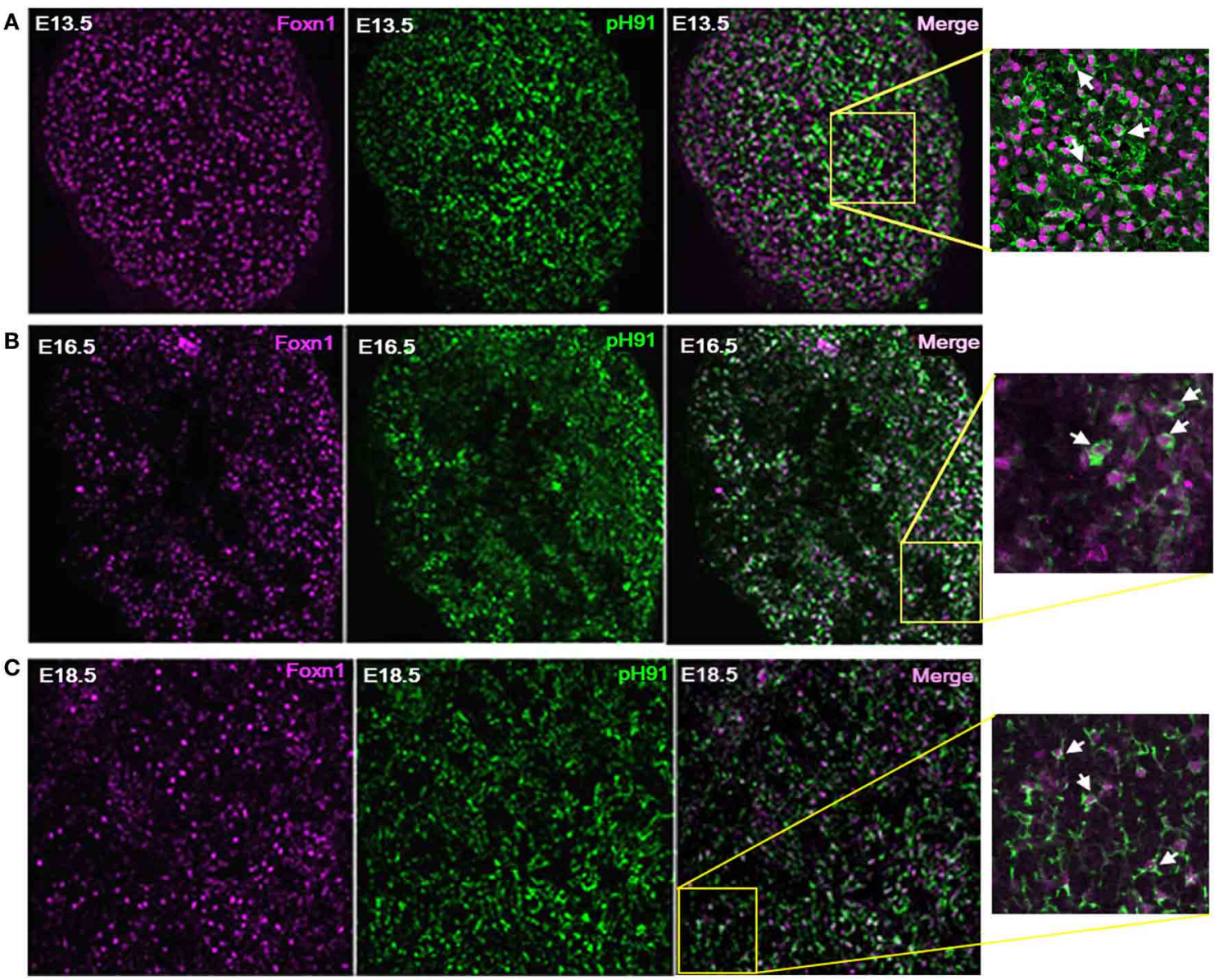

FIGURE 3 | (Continued) 


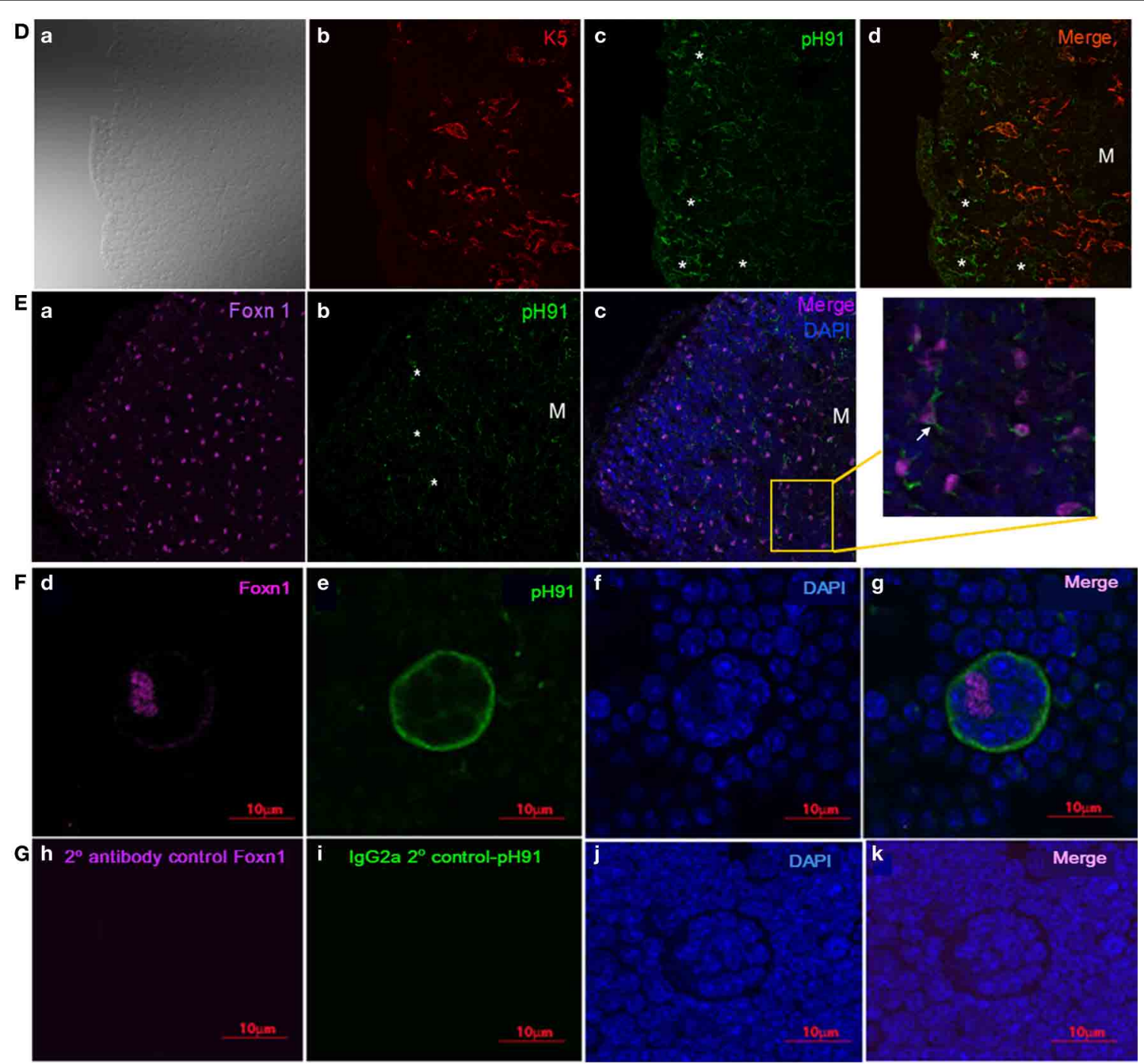

FIGURE 3 | Expression of Foxn1 and the pH91-antigen in embryonic sections. Thymic section at embryonic stage E13.5 (A), E16.5 (B), and E18.5 (C) were stained with anti-Foxn1 antibody (magenta) and pH91mAb (green). The merged images and insets (A-C), E13.5; E16.5; and E18.5 show an association of $\mathrm{pH} 91^{+}$cells with Foxn $1^{+}$cells. Magnification $20 \times$. (D) shows thymic section co-stained with $\mathrm{K} 5$ (red) and pH91 (green), The asterisks highlight $\mathrm{pH} 91^{+}$cells within the thymic cortex. $\mathrm{M}$ indicates the location of the medulla. Magnification 40x. (Ea-c) shows the expression of Foxn1 and pH91 in thymic tissue section 2 weeks after birth. Sections were stained with
anti-Foxn1 (magenta); pH91 (green). (Ec) show merged image and insets of pH91+ cells in association with Foxn1 (Arrow). Magnification 40x. (F) shows the expression of Foxn1 in pH91 ${ }^{+}$TNC ex vivo: Using antibody against Foxn1, expression was observed ex vivo in the TNCs. Foxn1 nuclear localization is seen only within TNC nucleus (Fd). pH91 staining is detected $(\mathbf{F e})$, DAPI nuclear staining (Ff) and the merged image is represented in $(\mathbf{F g})$. Thymocytes do not show Foxn1 expression. (G) shows secondary antibody controls for Foxn1 (Gh) and pH91 (Gi), All images represent 3 independent experiments. Magnification $40 x$ concomitant expression of $\mathrm{pH} 91$ with Foxn 1 is detectable in cells of the thymic-parathyroid primordium at E11.5 (Figure 2A; inset, lower panel). Similarly, at E12.5 the expression of Foxn1 was also observed with the $\mathrm{pH} 91$-antigen throughout the thymic anlagen (Figure 2B). The expression of Foxn 1 at this stage of development is consistent with previously published data (Gordon et al., 2001). When we enumerated and compared the phenotypic subtypes of cells present at E11.5 or E12.5, we found cells exhibiting the $\mathrm{pH}^{-} 1^{-} / \mathrm{Foxn}^{+}$phenotype to be significantly represented $(78.5 \%)$ when compared to the other subsets (Figure 2C). However, by E12.5 we observed a reduction the $\mathrm{pH} 91^{-} / \mathrm{Foxn}^{+}$ phenotype, while cells expressing the $\mathrm{pH} 91^{+} / \mathrm{Foxn}^{+}$phenotype show a significant increase (Figure 2C). We then examined the ontogenic expression of both Foxn 1 and the pH91-antigen in thymic sections obtained at E13.5 through 2 weeks of age. At E13.5 stage of development, Foxn1 and the pH91-antigen expression was detectable (Figure 3A, left and middle panels). The merged image shows the co-localization of both Foxn 1 and pH91-antigen in a subset of cells (Figure 3A, right panel). Similar expression patterns for Foxn 1 and $\mathrm{pH} 91$-antigen were observed at E16.5 and E18.5 (Figures 3B,C). Upon examination of the postnatal thymus (Figures 3D,E), we observed an association of 
Foxn 1 and pH91-antigen. Foxn1+ cells are visible throughout the thymic cortex as well as within the medullary islet (Figure 3E and inset). The presence of $\mathrm{pH}^{+} 1^{+}$cells are primarily seen in the cortex (Figures 3D,E) and in association with Foxn $1^{+}$cells (Figure 3Ec and inset). Finally, we examined TNCs ex vivo for the presence of Foxn1 and pH91-antigen, we found the Foxn1 transcription factor localized within the nucleus of $\mathrm{pH} 91^{+} \mathrm{TNCs}$ (Figures 3Fd-g).

\section{CO-EXPRESSION OF Foxn1 AND p63 IN pH91 + TEC}

The downstream targets of p63 and Foxn1 are not completely known. However, both transcription factors are required for maintenance and growth of the thymus (Gray et al., 2006;
Senoo et al., 2007). We examined embryonic tissue and isolated TNCs for the expression of both transcription factors. At E12.5 stage of thymic development, p63 expression is readily detected along with the pH91-antigen (Figure 4A). The expression of p63 persisted throughout embryonic developmental (Figures 4B-D; E13.5, E16.5, and E18.5) and continued expression was observed in the postnatal thymus (Figure 4E). The inset of the merged image shows in situ TNCs with nuclear localized p63 (Figure 4E, right panel). E12.5 sections stained with secondary antibody to p63 or pH91 shows no detectable expression of either marker (Figure 4F). DAPI stained nuclei are clearly visible in panels (Figure 4F, 3rd panel and merge). When $\mathrm{pH} 91^{+} \mathrm{TNCs}$ were costained with both Foxn1 and p63, we detected the expression
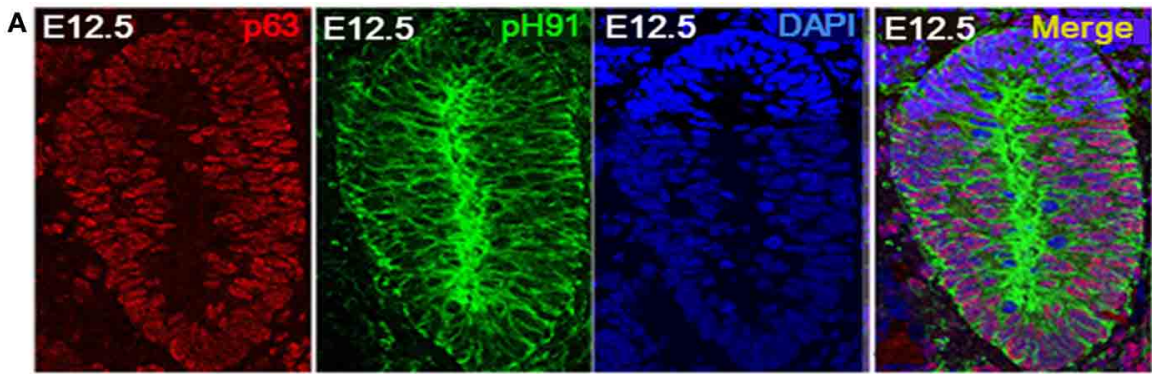

B

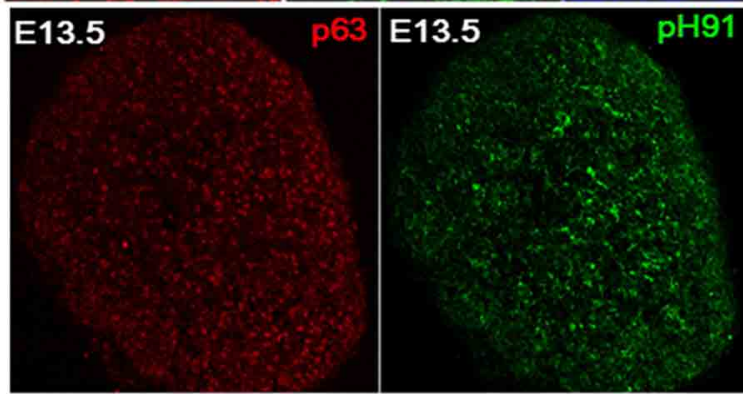

E13.5

Merge
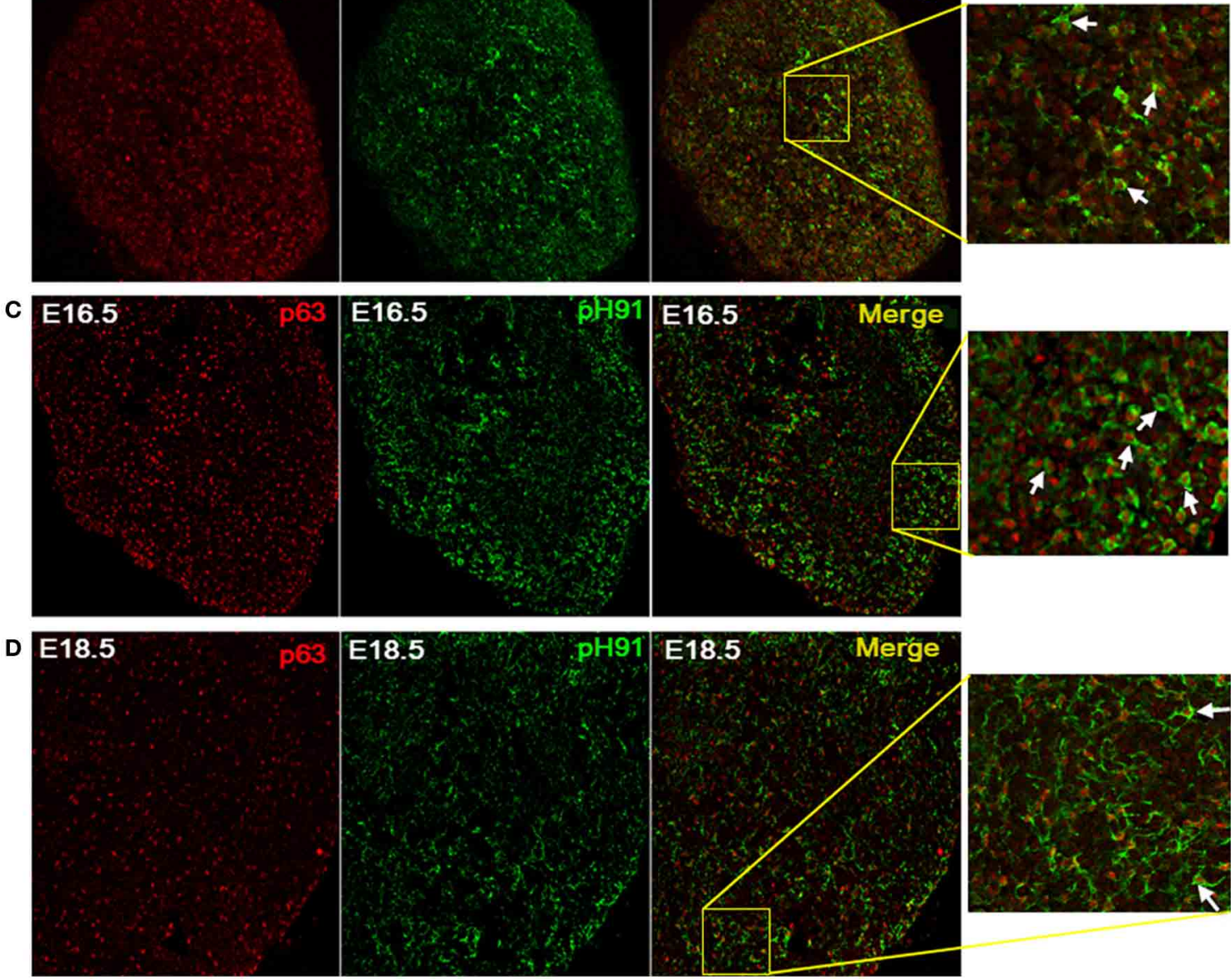

FIGURE 4 | (Continued) 

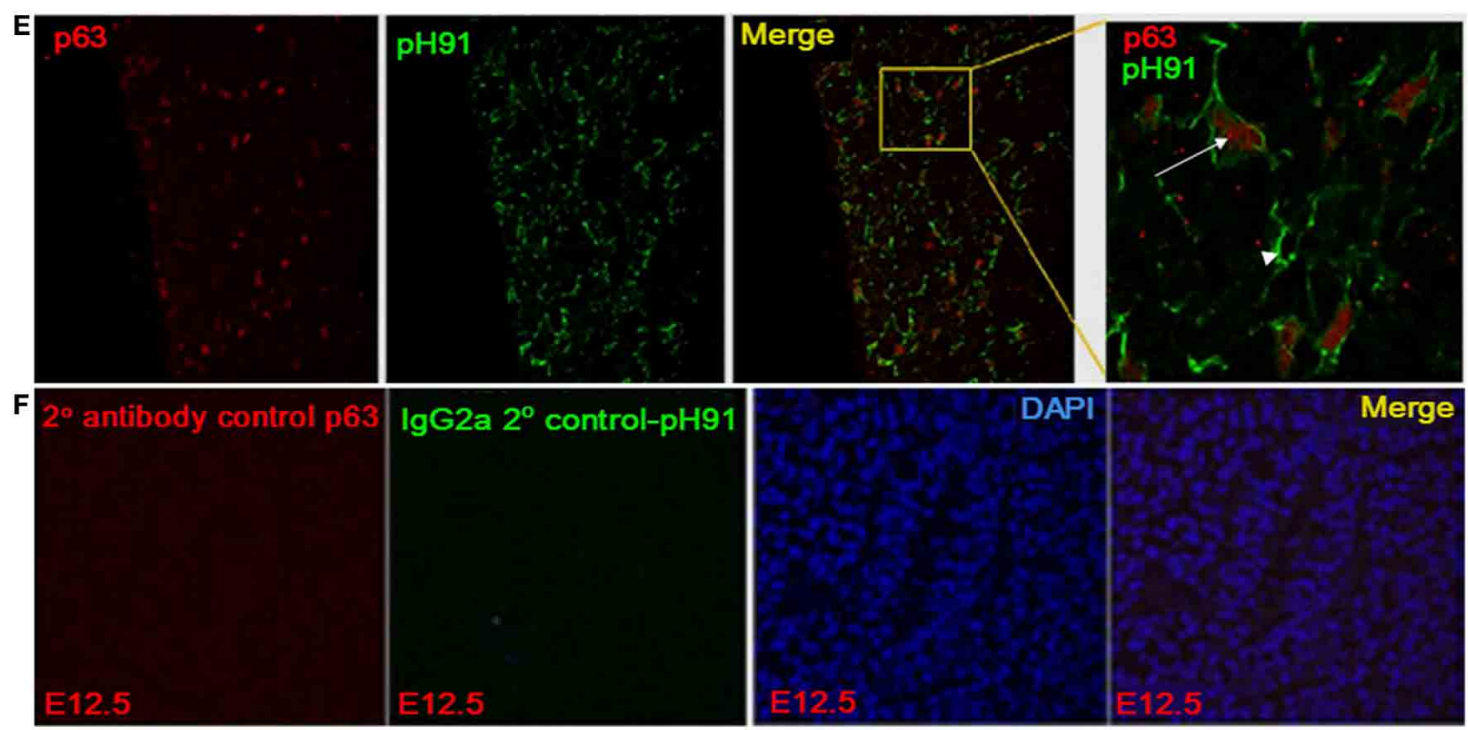

FIGURE 4 | Expression of p63 by pH91+ TECs. (A) shows thymic anlagen at E12.5 stage of development (sagittal section). Sections were stained with antibodies against p63 (red), pH91 (green), and DAPI (blue). Merged images at each developmental stage are shown in the right subpanels. Expression of $\mathrm{p} 63$ is seen in the nucleus of $\mathrm{pH} 91^{+}$epithelial cells. (B-E) show stained thymic sections with anti-p63 (red) and pH91 (green) at embryonic stages E13.5, E16.5, E18.5 and 2 weeks after birth respectively. Merged images and inset (B-D) show $\mathrm{pH} 91^{+}$cell expressing p63 (arrow). (E) shows $\mathrm{pH} 1^{+}$cell expressing p63 (arrow) and $\mathrm{pH} 1^{+}$cells that do not express p63 (arrow head). (F) shows the secondary antibody and isotype control for p63 (red) and pH91 (green) respectively.

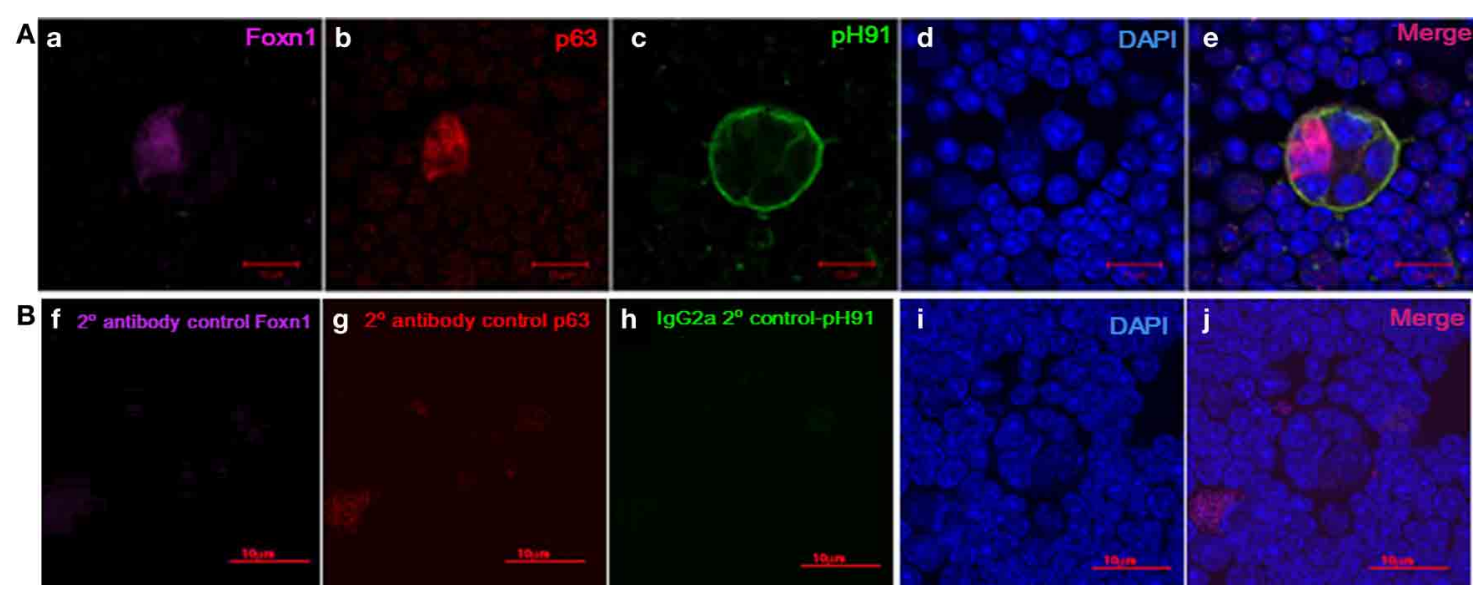

FIGURE 5 | Expression of Foxn1 and p63 in freshly isolated pH91+ multicellular TNCs ex vivo. (Aa) shows ex vivo TNC stained with anti-Foxn1 antibody. (Ab) shows ex vivo TNC stained with anti-p63 antibody. (Ac) shows ex vivo TNC stained with pH91 mAb antibody. (Ad) DAPI stained nuclei. (Ae) shows merged image of all three stains. (Bf-j) represents antibody controls for Foxn1, p63, and pH91. Magnifications 40x. of these two transcription factors within the nuclei of the cells examined (Figures 5 Aa-e).

To determine the frequency of $\mathrm{pH} 91^{+} \mathrm{TNC}$ that express Foxn 1 and $\mathrm{p} 63$, we manually counted the number of TNC-complexes that expressed both transcription factors in embryonic and adult mice (Figures 6A,B). During the early stages of development, by E 13.5, there is no significant difference between the expression of Foxn1 and p63 (94 and 92\% respectively) (Figure 6A). An evaluation of samples obtained at stage E16. 5 and E18.5 show significant decrease in p63 expression (Figure 5A). Conversely, the Foxn1 expression decreased significantly from E13.5 to E16.5 but rebounded from E16.5 to E18.5 (80.4-86\%) (Figure 6A). In neonatal mice, approximately $83 \%$ of $\mathrm{pH} 91^{+}$TNCs were found to express both Foxn 1 and p63 whereas, $12.35 \%$ of TNCs were found to be Foxn $1^{+} \mathrm{pH} \mathrm{1}^{+} \mathrm{p} 63^{-}$(Figure 6B).

\section{THE EXPRESSION OF PH91-ANTIGEN IN THE DEVELOPMENTAL APPEARANCE OF THE TNC MULTICELLULAR COMPLEXES}

At E13.5 we isolated TECs from embryonic thymi by enzymatic digestion. The resulting cells were visualized microscopically after staining with $\mathrm{pH} 91$ antibody. Although $\mathrm{pH} 91^{+}$cells were detectable, multicellular complexes were not evident at 

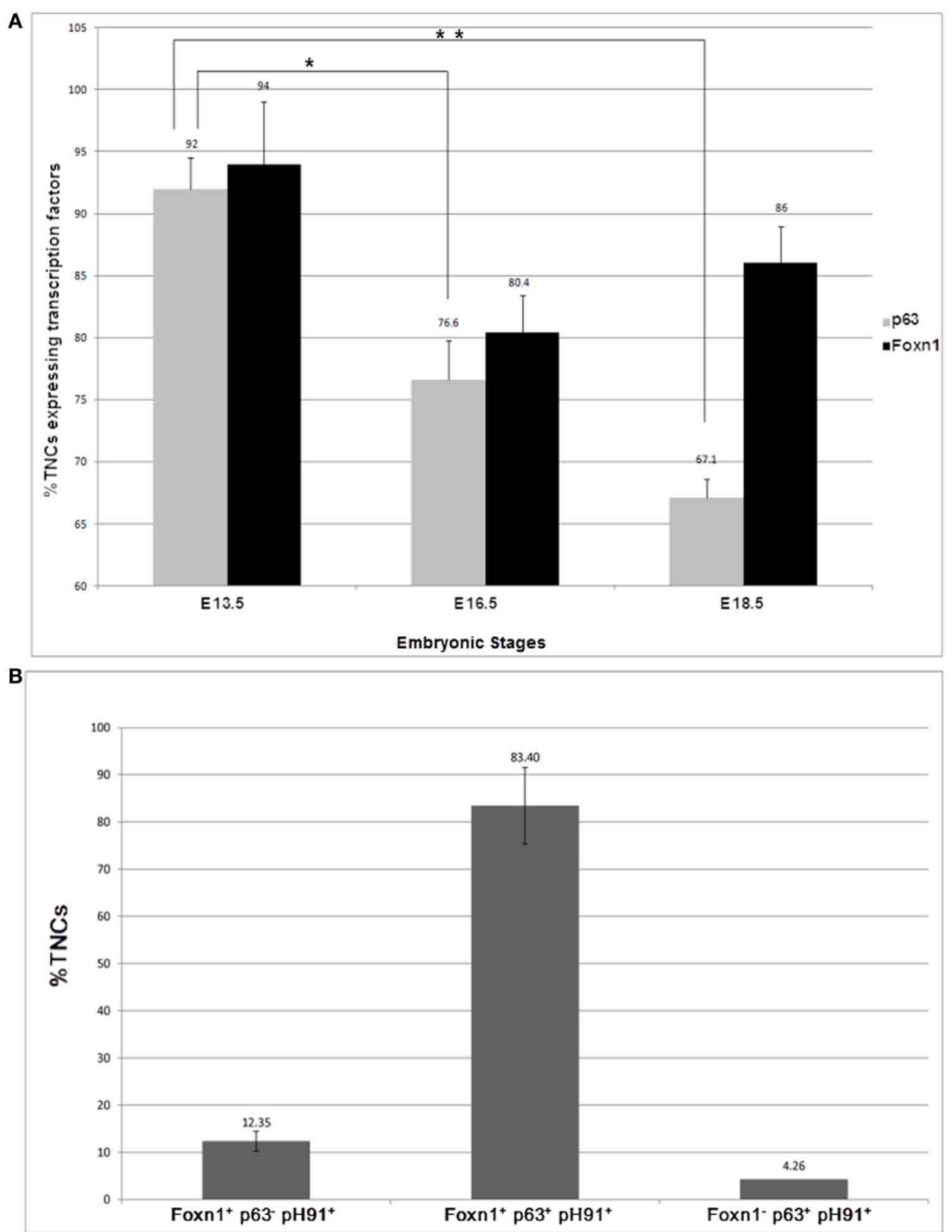

FIGURE 6 | Quantification of $\mathrm{pH}^{+}{ }^{+}$multicellular TNCs expressing the transcription factors Foxn1 and p63. $\mathrm{pH} 1^{+}$multicellular TNCs were isolated from, thymi from $\mathrm{C} 57 \mathrm{BL} / 6$ mice at embryonic stages of development E13.5, E16.5, and E18.5, cyto-spun onto slide and quantified manually with respect to expression of Foxn1, p63 and pH91. (A) shows the embryonic expression of p63 and Foxn1 by pH91 ${ }^{+}$cells. (B) shows expression of p53 and Foxn 1 by freshly isolated TNCs ex vivo. These data represent the results (mean \pm standard deviation) collected from three independent experiments with three animals per group $(n=9) .{ }^{*} P<0.05$ compared E13.5 with E16.5. ** $P<0.01$ compared E13.5 and E18.5. Statistical significance ( $t$-test). developmental stages E13.5 and E14.5 (Figures 7A,B). Cells positive for the $\mathrm{pH} 91$ antibody during development displayed different phenotypes. Some of the cells were bi-nucleated suggesting cellular division (Figure 7A, arrow), while others showed fibrous extensions (Figure 7B, arrow), characteristic of TNCs isolated from adult mice. The first multicellular complexes become visible at E17.5 (Figure 7C). All of the cells expressed the pH91 antigen. These complexes contained $\mathrm{CD} 4^{+} \mathrm{CD}^{+}$double positive thymocytes (Figure 7D). Developmentally, we then examined the time-line for the expression of MHC class II on the surface of these $\mathrm{pH}{ }^{+}$cells (Figure 7E). At the E13.5 stage, approximately $32 \%$ of the total population of cells analyzed was $\mathrm{pH} 91^{+} \mathrm{MHC}$ class $\mathrm{II}^{\text {low }}$ whereas $32 \%$ of the total population of cells analyzed was $\mathrm{pH}^{+}{ }^{+} \mathrm{MHC}$ class $\mathrm{II}^{\text {hi }}$. By stage E16.5 $\mathrm{pH}^{+}{ }^{+}$cells show increased expression of MHC class II on their surfaces, 31\% MHC class $\mathrm{II}^{\text {low }}$ and $64 \%$ MHC class II ${ }^{\text {hi }}$ (Figure 7E). By embryonic stage E18.5 approximately $66 \%$ of $\mathrm{pH}^{+} 1^{+}$cells expressed MHC class $\mathrm{II}^{\text {hi }}$ levels and about $27 \%$ of $\mathrm{pH}^{+}{ }^{+}$cells were MHC class 
II $^{\text {low }}$ (Figures 7E,G). Alternatively, when we compared the relative levels of MHC class II ${ }^{\text {hi }}$ expressed at E13.5, E16.5, and E18.5 using mean fluorescence intensity (MFI), we observed relative increases in MHC class II levels, respectively (Figure 7F).

\section{DISCUSSION}

The thymus is an organ that has been shown to have the ability to undergo regeneration upon injury and irradiation (Popa et al., 2007). This finding suggests that the thymus contains a population of epithelial cells that maintains progenitor function and this function has been shown to persist throughout adulthood and maintain the ability to proliferate and differentiate (Gray et al., 2006). Popa et al. have also shown that $\mathrm{K}^{+} \mathrm{K} 5^{+}$epithelial cells have the potential to differentiate into mature TECs as well (Popa et al., 2007). Their studies also suggested that $\mathrm{K}^{+} \mathrm{K}^{+}$thymic epithelial progenitors reside in the
CMJ (Popa et al., 2007). In a previous publication (Hendrix et al., 2010), we showed that a subset of TNCs are indeed double positive for K5 and K8 cytokeratins, and are strategically positioned within the CMJ of the thymus. The data reported here propose that TNCs have the characteristics of cells previously shown to proliferate and differentiate into mature cortical and medullary TECs.

To explore progenitor potential of TNCs, we used the antibody pH91 to verify along with their distinctive multicellular morphology that the cells of interest were in fact TNCs. First, cells isolated from adult animals with the characteristic TNC phenotype were shown to express $\mathrm{K} 5, \mathrm{~K} 8$, and pH91 (Figure 1A, Hendrix et al., 2010). However, it must be pointed out that although the antigen to which pH91 binds is co-expressed with $\mathrm{K}^{+} \mathrm{K}^{+}$by E12.5 stage of development (Figure 6A), the multicellular complexes that define TNCs are only identifiable at day

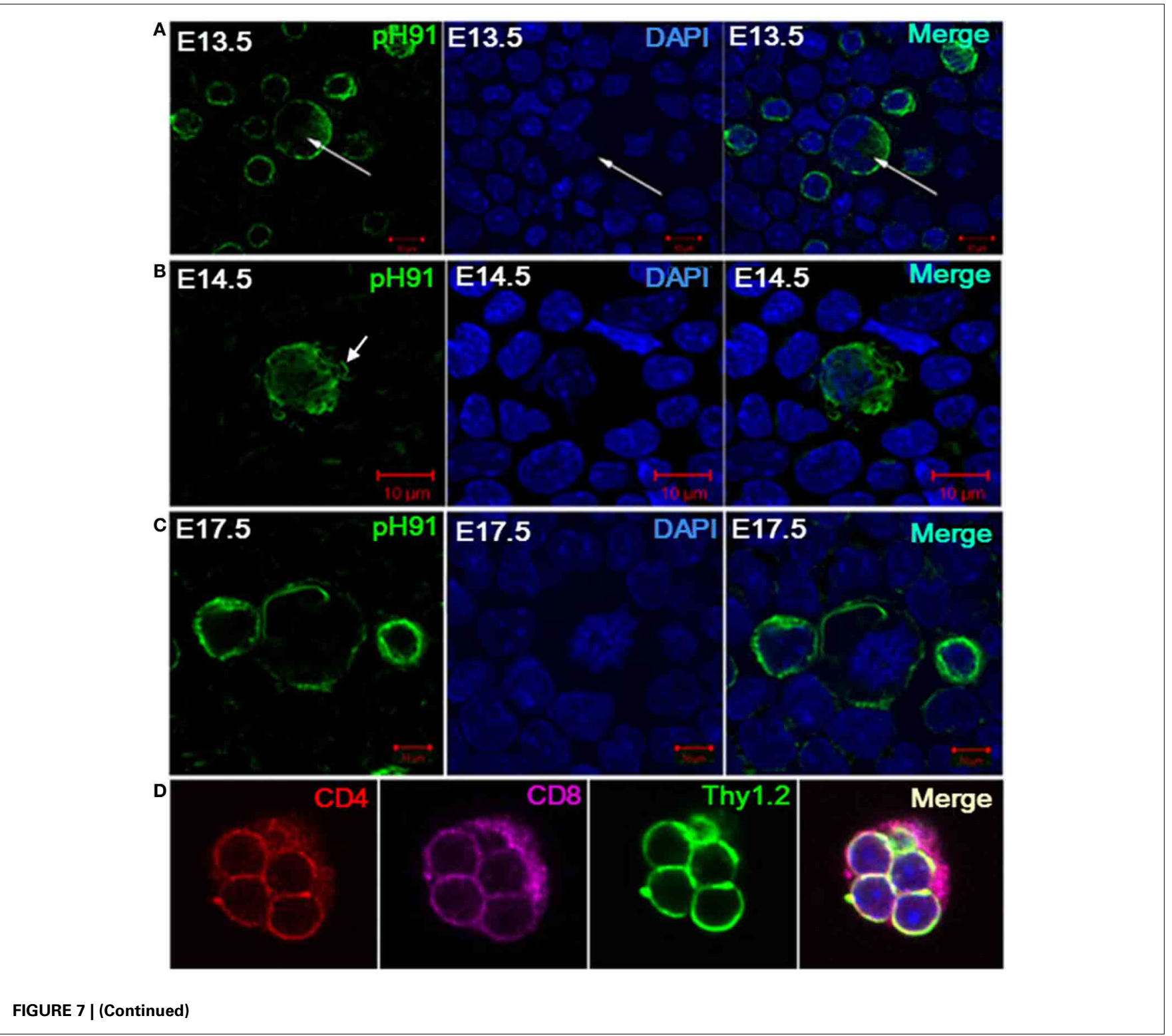




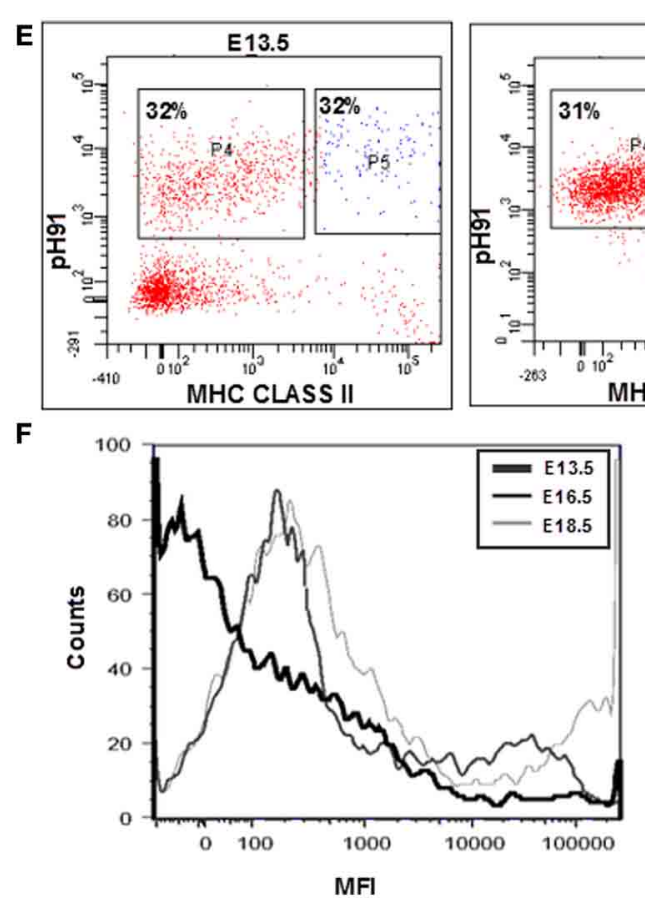

FIGURE 7 | Ontogeny expression of MHC Class II on the cell surfaces of multicellular TNCs. The development of TNCs was followed embryonically beginning at E13.5. TNCs were isolated from stages E13.5, E14.5, and E17.5. Isolated cells were cyto-spun onto glass slides and stained with $\mathrm{pH} 91$ antibody (green) and DAPI (blue), $\mathrm{pH} 91^{+}$cells were seen at different stages of cell cycle. (A) shows bi-nucleated cells (arrows). (B) shows TNCs expressing fibrous extensions (arrow). (C) shows $\mathrm{pH}^{+} 1^{+}$cells undergoing division. (D) shows a small TNC complex isolated from an E17.5 embryo. The TNC is seen with internalized
E16.5

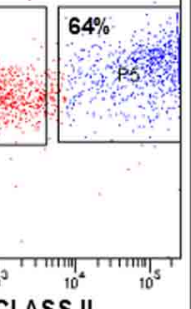

$\mathbf{G}$

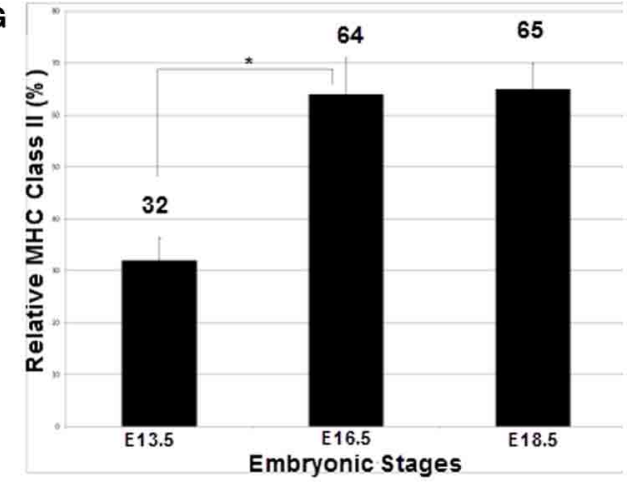

CD4 ${ }^{+}$CD8 ${ }^{+}$Thy $1.2^{+}$thymocytes. (E) shows FACS analysis for the expression of $\mathrm{pH} 91$ and $\mathrm{MHC}$ class $\mathrm{II}$ by isolated multicellular $\mathrm{pH}^{+}{ }^{+}$ TNCs at embryonic stages E13.5, E16.5, and E18.5. (F) shows the relative expression of $\mathrm{MHC}$ class $\mathrm{II}$ by $\mathrm{pH}^{+}{ }^{+}$cells as a function of mean

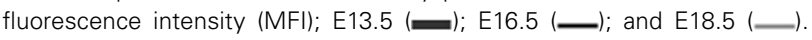
(G) shows a statistical significance of MHC expression between E13.5 and E16.5 as well as between E13.5 and E18.5 (*p-value < 0.05). Data are representative of three repeated experiments. (A-C) Magnification $40 \times$. (D) Magnification $63 \times$.
E17.5 (Figure 7C). We propose that the pH91-expressing epithelial cells (non-multicellular) in the early embryo become multicellular through the initial entoses event by E17.5. Our proposal is strengthened by data that show early $\mathrm{pH} 91^{+}$(non-multicellular) population and the late $\mathrm{pH}^{+} 1^{+}$(multicellular) subset to have identical phenotypes for K8, K5, Foxn1, and p63.

Data obtained throughout embryonic development and after birth show a large percentage of pH91-expressing cells to co-express the transcription factors p63 and Foxn1 (Figures 6A,B). With regards to p63, these results suggest that $\mathrm{pH} 91$-expressing cells have proliferative potential. Foxn1 expression occurs very early in the development of the thymus (Gordon et al., 2001). Foxn1 is an important transcription factor for thymic organogenesis (Gordon et al., 2001), and is expressed by the bi-potent $\left(\mathrm{K}^{+} \mathrm{K}^{+}\right)$thymic epithelial cells that have been reported to give rise to mature cTECs or mTECs (Bleul et al., 2006; Senoo et al., 2007; Corbeaux et al., 2010). Further, the expression of Foxn1 is indispensable for attracting lymphoid progenitors into the thymic anlagen and for the cross-talk initiated differentiation of thymic epithelial cells (Gordon et al., 2001; Manley and Condie, 2010).

Foxn1 was first observed in the thymic-parathyroid primordium around E11.25 in a small subset of epithelial cells, with increased expression by E11.75 (Gordon et al., 2001; Manley and Condie, 2010). The expression of Foxn1 was observed in the nucleus of $\mathrm{pH} 91^{+}$cells in the thymic primordium on day E11.5 (Figure 2), Foxn1 positive only cells were also observed. The expression of the $\mathrm{pH} 91$-antigen throughout the thymic-parathyroid primordium suggests that it may be a marker for cells that give rise to both the para-thyroid and thymus. However, the pH91 antigen as well as Foxn1 and p63 only separates with thymic tissue destined to become thymus and is undetectable within the parathyroid (Figure 2). Developmentally, the cytoplasmic membrane expression of the pH91-antigen initiates at about the same time as the nuclear expression of Foxn1. The association of $\mathrm{pH} 91$ and Foxn1 is observed throughout the neonatal stages of development (Figures 2, 3, 5, 6). This observation is important because Foxn1 expression is not only required for thymic epithelial cell specification but also critical to postnatal thymic function (Gray et al., 2006; Chen et al., 2009; Cheng et al., 2010). This notion is supported by the findings of Corbeaux et al. (2010) that showed only Foxn1 positive cells are capable of promoting thymopoiesis in the postnatal thymus. Our data show that these same cells express $\mathrm{pH} 91$.

The lympho-epithelial structure that defines TNCs was first described in 1980 (Wekerle and Ketelsen, 1980; Wekerle et al., 
1980). TNCs were shown to express major compatibility complex (MHC) class I and class II on their cell surfaces (Wekerle and Ketelsen, 1980) as well as surfaces enclosing thymocytes believed to undergoing MHC-restriction. The expression of class II MHC antigen by TNCs along with the autoimmune regulator (Aire) and tissue-restricted antigens (TRAs) provided strong support to the idea that TNCs participate in both positive and negative thymocyte selection (Wekerle and Ketelsen, 1980; Samms et al., 1999; Martinez et al., 2007; Hansenne et al., 2009). The experiments performed here revealed that $\mathrm{pH}{ }^{+}$cells began expressing high levels of class II MHC in the embryo shortly after internalizing triple positive thymocytes for the first time (66\%) (Figures 7E,F). These data suggest that the mouse thymus is competent for MHC restriction by E17.5 (Figure 7D). Collectively, our data suggest that throughout ontogeny, $\mathrm{pH} 91^{+}$epithelial cells co-express those antigens associated with thymic epithelial progenitors. These same cells internalize developing thymocytes to form the multicellular complexes that distinguish TNCs from other cell types of the mouse thymus, and soon after this initial entoses event, begin to express high levels of MHC class II antigen which is required for MHC restriction.

\section{ACKNOWLEDGMENTS}

We would like to thank Mr. Zacharia Olushoga for his technical expertise in the production of figures for the manuscript and Mr. Andrew Blake for the production of the pH91 ascites and Mr. Jeffrey Walker for his assistance with FACS analyses. We wish to also thank Dr. Jorge Morales for his microscopy expertise. A special thanks to Mr. Gregory Saunders for the intangibles that he brings into our research lives every day. This publication was made possible by grants from the National Center for Research Resources (2G12RR03060-26A1) and the National Institute on Minority Health and Health Disparities (8G12MD007603-28) from the National Institutes of Health. This project was also supported by grants from the National Center for Research Resources (2G12RR03060-26A1) and the National Institute on Minority Health and Health Disparities (8G12MD007603-28) from the National Institutes of Health.

\section{REFERENCES}

Alves, N. L., Takahama, Y., Ohigashi, I., Ribeiro, A. R., Baik, S., Anderson, G., et al. (2014). Serial progression of cortical and medullary thymic epithelial microenvironments. Eur. J. Immunol. 44, 16-22. doi: 10.1002/eji.2013 44110

Baik, S., Jenkinson, E. J., Lane, P. J., Anderson, G., and Jenkinson, W. E. (2013). Generation of both cortical and Aire $(+)$ medullary thymic epithelial compartments from CD205(+) progenitors. Eur. J. Immunol. 43, 589-594. doi: 10.1002/eji.201243209

Biggs, W. H., Meisenhelder, J., Hunter, T., Cavenee, W. K., and Arden, K. C. (1999). Protein kinase B/Akt-mediated phosphorylation promotes nuclear exclusion of the winged helix transcription factor FKHR1. Proc. Natl. Acad. Sci. U.S.A. 96, 7421-7426. doi: 10.1073/pnas.96.13.7421

Blanpain, C., and Fuchs, E. (2007). p63: revving up epithelial stem-cell potential. Nat. Cell Biol. 9, 731-733. doi: 10.1038/ncb0707-731

Bleul, C. C., Corbeaux, T., Reuter, A., Fisch, P., Mönting, J. S., and Boehm, T. (2006). Formation of a functional thymus initiated by a postnatal epithelial progenitor cell. Nature 441, 992-996. doi: 10.1038/nature04850

Candi, E., Rufini, A., Terrinoni, A., Giamboi-Miraglia, A., Lena, A. M., Mantovani, R., et al. (2007). DeltaNp63 regulates thymic development through enhanced expression of FgfR2 and Jag2. Proc. Natl. Acad. Sci. U.S.A. 104, 11999-12004. doi: $10.1073 /$ pnas.0703458104
Chen, L., Xiao, S., and Manley, N. R. (2009). Foxn1 is required to maintain the postnatal thymic microenvironment in a dosage-sensitive manner. Blood 113, 567-574. doi: 10.1182/blood-2008-05-156265

Cheng, L., Guo, J., Sun, L., Fu, J., Barnes, P. F., Metzger, D., et al. (2010). Postnatal tissue-specific disruption of transcription factor FoxN1 triggers acute thymic atrophy. J. Biol. Chem. 285, 5836-5847. doi: 10.1074/jbc.M109.072124

Corbeaux, T., Hess, I., Swann, J. B., Kanzler, B., Haas-Assenbaum, A., and Boehm, T. (2010). Thymopoiesis in mice depends on a Foxn1-positive thymic epithelial cell lineage. Proc. Natl. Acad. Sci. U.S.A. 107, 16613-16618. doi: 10.1073/pnas.1004623107

Gill, J., Malin, M., Holländer, G. A., and Boyd, R. (2002). Generation of a complete thymic microenvironment by MTS24(+) thymic epithelial cells. Nat. Immunol. 3, 635-642. doi: 10.1038/ni812

Gillard, G. O., and Farr, A. G. (2006). Features of medullary thymic epithelium implicate postnatal development in maintaining epithelial heterogeneity and tissue-restricted antigen expression. J. Immunol. 176, 5815-5824.

Gordon, J., Bennett, A. R., Blackburn, C. C., and Manley, N. R. (2001). Gcm2 and Foxn 1 mark early parathyroid- and thymus-specific domains in the developing third pharyngeal pouch. Mech. Dev. 103, 141-143. doi: 10.1016/S09254773(01)00333-1

Gordon, J., Wilson, V. A., Blair, N. F., Sheridan, J., Farley, A., Wilson, L., et al. (2004). Functional evidence for a single endodermal origin for the thymic epithelium. Nat. Immunol. 5, 546-553. doi: 10.1038/ni1064

Gray, D. H., Seach, N., Ueno, T., Milton, M. K., Liston, A., Lew, A. M., et al. (2006). Developmental kinetics, turnover, and stimulatory capacity of thymic epithelial cells. Blood 108, 3777-3785. doi: 10.1182/blood-2006-02-004531

Hamazaki, Y., Fujita, H., Kobayashi, T., Choi, Y., Scott, H. S., Matsumoto, M., et al. (2007). Medullary thymic epithelial cells expressing Aire represent a unique lineage derived from cells expressing claudin. Nat. Immunol. 8, 304-311. doi: 10.1038/ni1438

Hansenne, I., Louis, C., Martens, H., Dorban, G., Charlet-Renard, C., Peterson, P., et al. (2009). Aire and Foxp3 expression in a particular microenvironment for $\mathrm{T}$ cell differentiation. Neuroimmunomodulation 16, 35-44. doi: 10.1159/000179665

Hendrix, T. M., Chilukuri, R. V., Martinez, M., Olushoga, Z., Blake, A., Brohi, M., et al. (2010). Thymic nurse cells exhibit epithelial progenitor phenotype and create unique extra-cytoplasmic membrane space for thymocyte selection. Cell. Immunol. 261, 81-92. doi: 10.1016/j.cellimm.2009.11.004

Klug, D. B., Carter, C., Crouch, E., Roop, D., Conti, C. J., and Richie, E. R. (1998). Interdependence of cortical thymic epithelial cell differentiation and T-lineage commitment. Proc. Natl. Acad. Sci. U.S.A. 95, 11822-11827. doi: 10.1073/pnas.95.20.11822

Klug, D. B., Carter, C., Gimenez-Conti, I. B., and Richie, E. R. (2002). Cutting edge: thymocyte-independent and thymocyte-dependent phases of epithelial patterning in the fetal thymus. J. Immunol. 169, 2842-2845.

Kops, G. J., de Ruiter, N. D., De Vries-Smits, A. M., Powell, D. R., Bos, J. L., and Burgering, B. M. (1999). Direct control of the Forkhead transcription factor AFX by protein kinase B. Nature 398, 630-634. doi: 10.1038/19328

Le Douarin, N. M., and Jotereau, F. V. (1975). Tracing of cells of the avian thymus through embryonic life in interspecific chimeras. J. Exp. Med. 142, 17-40. doi: 10.1084/jem.142.1.17

Manley, N. R. (2000). Thymus organogenesis and molecular mechanisms of thymic epithelial cell differentiation. Semin. Immunol. 12, 421-428. doi: 10.1006/smim. 2000.0263

Manley, N. R., and Condie, B. G. (2010). Transcriptional regulation of thymus organogenesis and thymic epithelial cell differentiation. Prog. Mol. Biol. Transl. Sci. 92, 103-120. doi: 10.1016/S1877-1173(10)92005-X

Martinez, M., Samms, M., Hendrix, T. M., Adeosun, O., Pezzano, M., and Guyden, J. C. (2007). Thymic nurse cell multicellular complexes in HY-TCR transgenic mice demonstrate their association with MHC restriction. Exp. Biol. Med. (Maywood) 232, 780-788.

Nehls, M., Kyewski, B., Messerle, M., Waldschütz, R., Schüddekopf, K., Smith, A. J., et al. (1996). Two genetically separable steps in the differentiation of thymic epithelium. Science 272, 886-889. doi: 10.1126/science.272.52 63.886

Ohigashi, I., Zuklys, S., Sakata, M., Mayer, C. E., Zhanybekova, S., Murata, S., et al. (2013). Aire-expressing thymic medullary epithelial cells originate from beta5texpressing progenitor cells. Proc. Natl. Acad. Sci. U.S.A. 110, 9885-9890. doi: $10.1073 /$ pnas. 1301799110 
Pezzano, M., King, K. D., Philp, D. D., Adeyemi, A., Gardiner, B., Yang, J., et al. (1998). A thymic nurse cell-specific monoclonal antibody. Cell. Immunol. 185, 123-133. doi: 10.1006/cimm.1998.1279

Pezzano, M., Philp, D., Stephenson, S., Li, Y., Reid, V., Maitta, R., et al. (1996). Positive selection by thymic nurse cells requires IL-1 beta and is associated with an increased Bcl-2 expression. Cell. Immunol. 169, 174-184. doi: 10.1006/cimm.1996.0108

Popa, I., Zubkova, I., Medvedovic, M., Romantseva, T., Mostowski, H., Boyd, R., et al. (2007). Regeneration of the adult thymus is preceded by the expansion of $\mathrm{K} 5+\mathrm{K} 8+$ epithelial cell progenitors and by increased expression of Trp63, $\mathrm{cMyc}$ and $\mathrm{Tcf} 3$ transcription factors in the thymic stroma. Int. Immunol. 19, 1249-1260. doi: 10.1093/intimm/dxm092

Samms, M., Philp, D., Emanus, F., Osuji, O., Pezzano, M., and Guyden, J. C. (1999). Lysosomal-mediated degradation of apoptotic thymocytes within thymic nurse cells. Cell. Immunol. 197, 108-115. doi: 10.1006/cimm.19 99.1559

Senoo, M., Pinto, F., Crum, C. P., and McKeon, F. (2007). p63 Is essential for the proliferative potential of stem cells in stratified epithelia. Cell 129, 523-536. doi: 10.1016/j.cell.2007.02.045

Wekerle, H., and Ketelsen, U. P. (1980). Thymic nurse cells-Ia-bearing epithelium involved in T-lymphocyte differentiation? Nature 283, 402-404. doi: $10.1038 / 283402 \mathrm{a} 0$
Wekerle, H., Ketelsen, U. P., and Ernst, M. (1980). Thymic nurse cells. Lymphoepithelial cell complexes in murine thymuses: morphological and serological characterization. J. Exp. Med. 151, 925-944. doi: 10.1084/jem.151. 4.925

Conflict of Interest Statement: The authors declare that the research was conducted in the absence of any commercial or financial relationships that could be construed as a potential conflict of interest.

Received: 11 December 2013; accepted: 24 March 2014; published online: 28 April 2014.

Citation: Chilukuri RVE, Patel VK, Martinez M, Guyden JC and Samms MD (2014) The antigenic determinant that defines thymic nurse cells is expressed by thymic epithelial progenitor cells. Front. Cell Dev. Biol. 2:13. doi: 10.3389/fcell.2014.00013 This article was submitted to Stem Cell Research, a section of the journal Frontiers in Cell and Developmental Biology.

Copyright (C) 2014 Chilukuri, Patel, Martinez, Guyden and Samms. This is an openaccess article distributed under the terms of the Creative Commons Attribution License (CC BY). The use, distribution or reproduction in other forums is permitted, provided the original author(s) or licensor are credited and that the original publication in this journal is cited, in accordance with accepted academic practice. No use, distribution or reproduction is permitted which does not comply with these terms. 